\title{
The One Reason You are Not Happy
}

\section{Ghedira Fatma* \\ Columbia University, USA}

Submission: August 14, 2017; Published: August 17, 2017

*Corresponding author: Ghedira Fatma, Columbia University, USA; Tel: 3233602979; Email: fg2393@tc.columbia.edu

\section{Short Communication}

I have always been drawn to this mystical concept called Happiness. Questions that obsessed me since childhood are: why do we need things to be happy? Why is the old lady in my neighborhood always in a good mood? Why are the most successful people unhappy?

I was never able to connect the dots. Then, I got to college and picked psychology as my major. Fortunately, this field exposed me to outstanding theorists and happiness experts. For instance, his holiness the Dalai Lama bases his own happiness on compassion and gratitude. It is good practice to do so because these traits help people focus on others rather than themselves. Then Yale President Peter Salovey and psychologist John Mayer popularized a psychological term called emotional intelligence. One of the early writers on the topic, psychologist and science journalist, Daniel Goleman asserts that having the right social and emotional skills can get you to where you want to be and therefore you become happier.

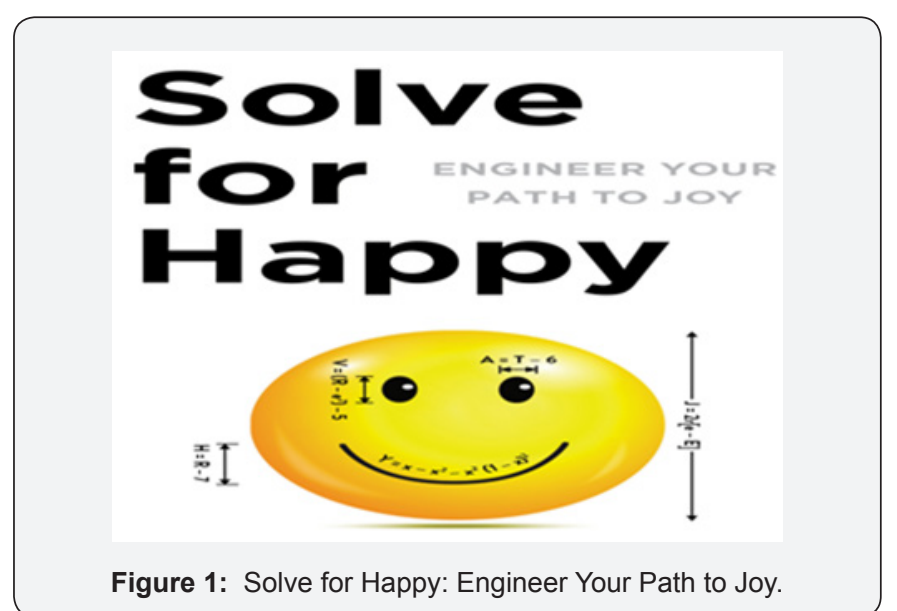

Even though I learned a great deal from the bright scholars I encountered throughout my academic career, I was more interested in knowing the logic behind happiness. Why were some people unhappy? How did I overcome those moments of despair? And what about those breakups that I never thought I would get over? How can I work on my emotions to be happy most of the time? In my career as a mental health professional, I have seen people suffering from various mental illnesses. What I noticed in all of them is that mental illness was not an issue in and of itself, but their suffering was (Figure 1).

Unfortunately, I can't go over all the things I learned through "Solve for Happy: Engineer Your Path to Joy," a book by Mo Gawdat, in one post. But what got me hooked in the first place is his logic. It made sense. Happiness is presented in this book in a form of guidelines explaining the darkest and most basic instinctive psychological misconceptions that cause our suffering. It starts with the origin of the issue of suffering and how to resolve it, or in Mo's words, how to "solve for it." Here is the one thing that shifted my mindset and helped me understand what underlies my personal suffering: Control.

Control is what every ambitious young man and woman suffers from. We want to control our time to be more efficient and more productive. We mostly want to control our career, our success, and achievement of our goals. I have always been into having full control over my life. But it became an acute need when I moved to New York. When I met Mo, I was at the peak of my control mania. I was going through finals, I had an internship, I was an active member in some clubs and I still wanted to reserve some time for things that meant a great deal to me such as happiness. Control for me was the only way I could make it through. I controlled my commute, I controlled my meals, my breaks, the time I would dedicate to school, to work and to the gym. My week was planned by the minute.

Don't get me wrong, I am not saying that being organized will make you unhappy. The root of the issue was deeper than that. But let's first talk about how control becomes an issue.

\section{When Control is the Absolute Ruler}

The notion that you need control to get through that to-do list is wrong. The problem is not the control you exercise over going 
through that list. It took me some time to realize while talking to Mo that the problem was the to-do list itself. He made me realize my tendency to relentlessly assign tasks to myself. Those tasks that only wonder Woman can accomplish in a week or even a month. As a result, I feel obligated to complete the list and if I didn't? I have it in the back of my head all day long, seven days a week. And when the list is not done by the deadline? Remorse and guilt become my companions. Finally, I would revisit all the things I have planned for the week and see where I wasted time and try harder the week after.

\section{Results}

I never was able to finish that list and I don't think I ever will. Mo pointed out how my unrealistic expectations were coming from the illusion of control and he explained it with a few notions that I see as the best combination of a happy mind shift.

\section{Localize Where Control Comes From}

In my case control came from the fact that I wanted to go over a to-do list that was more crowded than the beach on a hot summer day. But the origin of the controlling tendency comes from two things: my association of hard work with success and the tendency to self-assign tasks that sometimes are not needed.

\section{Acknowledging our Limited Control}

“Acknowledging our limited control shouldn't cause us to despair. It all starts with understanding the true nature of our control. We think we are in control of everything-our money, friends, and career. But, honestly, how much control do you really have over those things you're hanging on to?" Mo writes. What I did is, I started writing down all the things that I don't have a full control over only to realize that almost nothing is entirely under my control. It was an enlightening experience.

\section{Reflect on the Butterfly Effect}

Edward Lorenz, a meteorologist, coined the term 'butterfly effect' to make accessible a phenomenon that had been known for a while. The concept is derived from the metaphorical example of the origins of a tornado being influenced by the minor act of a butterfly flapping its wings. In other words, if the butterfly had not flapped its wings at just the right point in space/time, the tornado would not have happened. A more rigorous way to express this is: small changes in the initial conditions lead to drastic changes in the results. Our lives are an ongoing demonstration of this principle. Realizing that we are all surrounded by butterfly effects gives us the ease of giving up on trying to control. To my knowledge, butterflies are not the only insect which flaps its wings.

\section{Acknowledge Black Swans}

The statistician Nassim Nicholas Taleb developed a theory called "the black swan theory," a metaphor explaining the erroneousness of rationalizing events using hindsight. $\mathrm{He}$ describes black swan as all events that are outliers, are rare and have extreme impacts. Hurricane Katrina, for example, was one of those events. What Taleb and Mo tried to illustrate when they examined this phenomenon is our limitation on learning from observation, and the fragility of our ensuing knowledge. What struck me about this realization is that we all tend to think black swans happen to other people. But when they actually happen to us, we tend to think we are doomed (Figure 2).

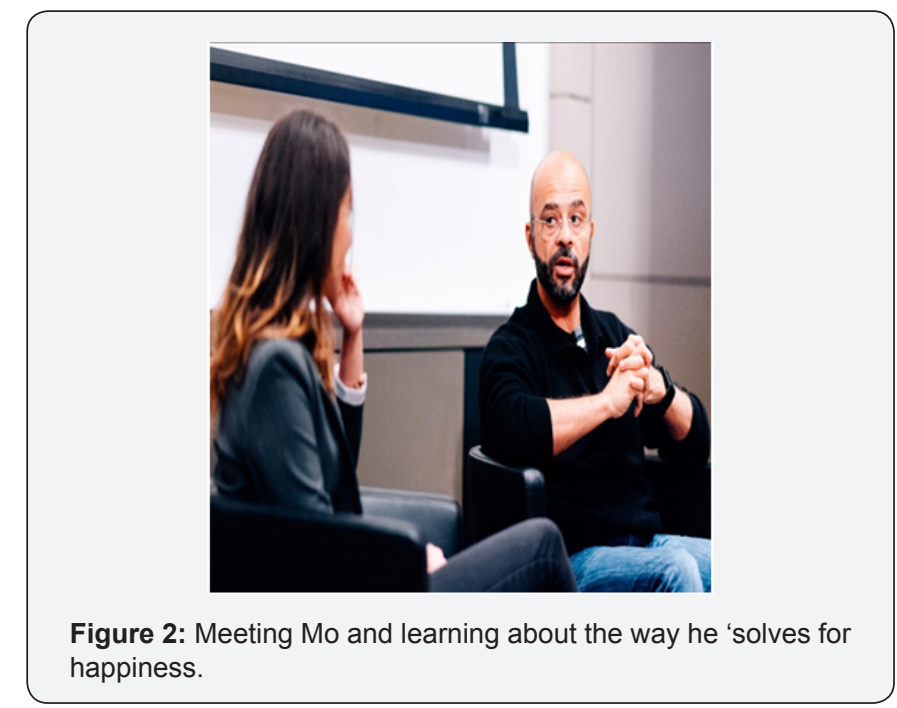

Meeting Mo and learning about the way he 'solves for happiness' has turned my world upside down. It has impacted me so much that we, together with my happiness enthusiast colleagues, have decided to have Mo visit for a full two-day training on happiness in New York. In this two-day workshop, Mo takes the time to share the underlying reasons for human suffering and plots out a step-by-step process for achieving lifelong happiness. Using an engineering approach to logic and problem solving, he proposes a "happiness equation" based on an understanding of how the brain takes in and processes joy and sadness. He'll share a series of practical activities to help you explore how the concepts apply specifically to you (Figure 3).

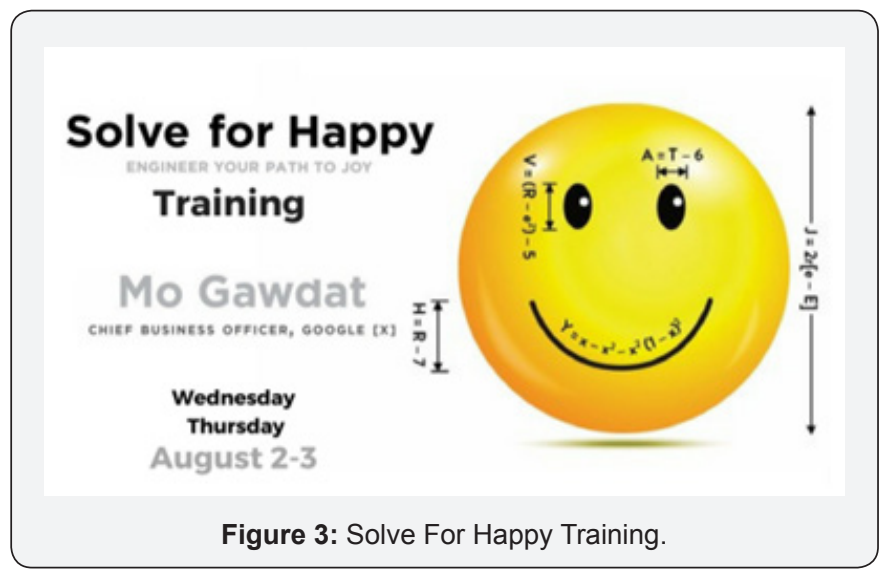

The workshop is based on his book, "Solve for Happy: Engineering Your Path to Joy." This work came as a result of a 
tough yet inspiring experience of suddenly losing his dear son, Ali. The workshop is part of Mo's personal mission to make ten million people happy.

This work is licensed under Creative Commons Attribution 4.0 License

DOI: 10.19080/PBSIJ.2017.05.555671
Mo uses an experiment-based interactive approach that allows you to experience for yourself the behaviors and patterns that lead to unhappiness. Once you see them clearly, they become easy to overcome.

\section{Your next submission with Juniper Publishers} will reach you the below assets

- Quality Editorial service

- Swift Peer Review

- Reprints availability

- E-prints Service

- Manuscript Podcast for convenient understanding

- Global attainment for your research

- Manuscript accessibility in different formats

( Pdf, E-pub, Full Text, Audio)

- Unceasing customer service

Track the below URL for one-step submission https://juniperpublishers.com/online-submission.php 